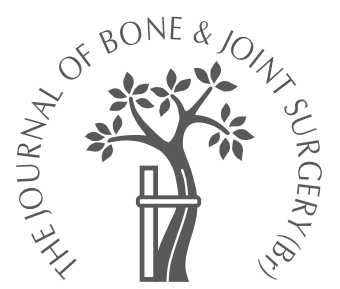

G. Maccauro,

C. Piconi,

W. Burger,

L. Pilloni,

E. De Santis,

F. Muratori,

I. D. Learmonth

From The Catholic

University, Rome,

Italy

G. Maccauro, MD

Orthopaedic Surgeon

C. Piconi, MSc, Professor

E. De Santis, MD, PhD

Orthopaedic Surgeon

F. Muratori, MD, Resident in Orthopaedics

Department of Orthopaedics,

Catholic University, via T.

Valfrè 12, Rome, Italy.

W. Burger, PhD, Head Oxide Materials Research Unit, CeramTec AG,

Fabrikstrasse 23-29,

Plochingen, Germany.

L. Pilloni, PhD, Researcher in Biomaterials

ENEA, Technologies and

Materials Unit, Casaccia

Research Centre, via

Anguillarese 301, Rome,

Italy.

I. D. Learmonth, FRCS

Professor

Department of Orthopaedic

Surgery, Bristol University,

Bristol BS2 8HW, UK.

Correspondence should be sent to Dr. G. Maccauro at Viale delle Medaglie d'oro

246, 00136 Rome, Italy.

(C)2004 British Editorial

Society of Bone and

Joint Surgery

doi:10.1302/0301-620X.86B8.

$15012 \$ 2.00$

$J$ Bone Joint Surg [Br]

2004;86-B:1192-6.

Received 20 October 2003

Accepted after revision

24 March 2004

\title{
Fracture of a Y-TZP ceramic femoral head
}

\author{
ANALYSIS OF A FAULT
}

We studied factors contributing to the initiation of fracture and failure of a zirconia ceramic femoral head. The materials retrieved during a revision total hip replacement were submitted to either visual, stereomicroscopic and scanning electron microscopy (SEM) or SEM and energy-dispersive $x$-ray analysis. X-ray diffraction was performed in order to investigate the extent of tetragonal to monoclinic phase transition. Histological examination was performed on the periprosthetic tissues.

The results showed that failure was due to the propagation during clinical use of defects which may have been introduced into the material during the processing of the ceramic, rather than those intrinsic to zirconia. The literature relating to previous failures of zirconia components is reviewed.

Zirconia ceramic (Y-TZP, Y-ttria-stabilised tetragonal zirconia polycrystal $)^{1}$ has been used for implantable devices because of its strength which is based on tetragonal-to-monoclinic (T-M) phase transition of the metastable tetragonal grains. ${ }^{2-4}$ The main application of zirconia as a biomaterial is in femoral heads for total hip replacement (THR) and a variety of other implantable devices in orthopaedics and dentistry $^{5-10}$ (Table I). To date, more than 500000 ceramic femoral heads have been made by manufacturers in Europe, Japan and the USA. ${ }^{2}$

There have been few reports in the literature of fractures of zirconia ${ }^{11-15}$ while several papers have reported wear of ultra-high molecular-weight polyethylene (UHMWPE) which is the standard counterface to zirconia heads, ${ }^{16-20}$ associated in some series with an increase in surface roughness or decrease in hardness ${ }^{21}$ with T-M surface phase transition. Some of these studies have reported that the zirconia heads were black in colour. This feature, which does not affect the mechanical properties, ${ }^{22}$ was observed in some early zirconia biomaterials and may have been due to surface reduction reactions during sintering or to the interaction of photons with rare earth impurities, such as praseodymium, during gamma sterilisation.

These observations caused anxiety about the risk of spontaneous T-M phase transition in zirconia ceramics which may occur to a variable extent, ${ }^{23}$ depending on the basic materials and mode of processing. It is also known that additives such as $\mathrm{CeO}_{2}$ or $\mathrm{Al}_{2} \mathrm{O}_{3}$ inhibit T-M transition ${ }^{24-26}$ as does the spatial distribution of the phase-stabilising oxide which occurs in yttria coated powder. ${ }^{27}$ With these considerations in mind we have investigated the cause and the mechanisms which led to the fracture of a zirconia femoral head 34 months after surgery.
Table I. Applications

\begin{tabular}{ll}
\hline Applications & Author/s \\
\hline $\begin{array}{l}\text { Cups in resurfacing } \\
\text { arthroplasties }\end{array}$ & Bioproimplants $^{5}$ \\
Carpometacarpal joints & Calandruccio and Jobe $^{6}$ \\
Dental implants & Kohal et al \\
Ceramic posts & Kakehashi et al \\
Bridges & Weber and Rieger \\
Crowns & Luthard et al ${ }^{10}$ \\
\hline
\end{tabular}

\section{Case report}

In May 1999, a $28 \mathrm{~mm}$ zirconia femoral head was implanted into a 58-year old patient in the course of replacement of the left hip because of osteoarthritis. It was applied to a cementless stem (Geomodular Medinov; DePuy, Warsaw, Indiana) and articulated with the UHMWPE insert of a metal-backed cup (Duraloc; DePuy) of diameter $52 \mathrm{~mm}$ ). Fixation of the socket was enhanced by three screws.

In 2000, the surgeon warned his patient about the risk of fracture of the ceramic head, following a hazard warning by the manufacturer of the prosthesis. However, the patient decided not to have his asymptomatic, well-functioning hip revised. In March 2002 he heard a sudden loud noise in the left hip followed by pain, limitation of movement and a 'click' during gait. He was seen two months later and radiographs (Fig. 1) showed fracture of the head into many fragments, with no sign of osteolysis.

During revision surgery, besides the shattered femoral head (Fig. 2), there was extensive metallosis in the periprosthetic tissues and severe damage to the taper of the stem. The THR was revised to a Furlong prosthesis (London, UK) with a cobalt-chromium head and a cementless socket, fixed by three 
screws. The post-operative recovery was uneventful and at followup at 15 months no problems had been encountered.

Analysis of materials. At the time of revision the socket, the stem, the fragments of the zirconia ball and periprosthetic tissues were retrieved and sent for analysis, following a specific protocol for prosthetic implant retrieval in accordance with the standard ISO $12891 .^{28,29}$ The materials underwent visual, stereomicroscopic and scanning electron microscopy (SEM) or SEM and energy-dispersive $\mathrm{X}$-ray analysis (EDAX).

Ceramic samples. Visual and stereomicroscopic analysis of ceramic fragments were used to detect the pattern of fracture. Selected sections were cut following a standard laboratory procedure designed to avoid subcritical crack growth during preparation, and then analysed by field emission gun scanning electron microscopy (FEG-SEM) (LEO 1520, Oberkochen, Germany) with a backscatter Centaurus detector (KE Developments, Cambridge, UK). The microstructure of the samples was observed on polished, uncoated surfaces after thermal etching at $1200^{\circ} \mathrm{C} /$ hour. Grain size was measured by SEM-coupled image analysis using the linear intercept method. The concentration of monoclinic phase in samples was measured by x-ray (D 8Advance; Brucker AXS, Madison, Wisconsin) linked to Diffrac software (Brucker AXS).

Tissue samples. Periprosthetic tissue membranes were studied using optical microscopy in transmitted and polarised light and by EDAX-coupled SEM (Philips 515, Eindhoven, The Netherlands). Samples for transmitted and polarised light microscopy were fixed in $10 \%$ formalin, decalcified in ethylenediaminetetracetate, dehydrated and embedded in paraffin, sectioned into slices 3 to $5 \mu \mathrm{m}$ in size and stained with haematoxylin and eosin. Tissue specimens for SEM were fixed in Karnosky's solution, dehydrated using increasing concentrations of ethanol $(70 \%, 75 \%, 95 \%$ and $100 \%$ ), then covered with colloidal palladium. EDAX was used to detect the chemical composition of the debris.

\section{Results}

Visual inspection. At the time of revision surgery, fracture of the Y-TZP femoral head, coupled with extensive abrasion of the taper and damage of the UHMWPE liner, were observed. The metal back did not appear to be abraded. The most striking feature was the extensive metallosis in the periprosthetic tissues. The retrieved fragments of the zirconia head are shown in Figure 2. The external spherical surface of the femoral head and its fracture surfaces showed transferred metal layers.

Pattern of fracture. The revision surgery was performed two months after the failure of the head. In the interval rubbing of fragments against each other and against the taper induced chipping and further damage to the surfaces of the fracture. Moreover, several small fragments were lost during revision surgery.

Laboratory tests have shown that the primary fracture of ceramic heads is characteristically parallel to the main axis of the head. ${ }^{30}$ In our retrieved fragments this feature was observed in only one fracture surface; the counterface was lost. The taper surface was damaged in all fragments. In the largest fragment its surface was severely worn indicating degradation of material properties in the core of the ceramic head.

X-ray diffraction of the ceramic fragments. Monoclinic phase concentration on the originally polished external surface was limited to about $4 \%$, while concentrations of up to $60 \%$ were measured on the taper surface. On the other hand, the ceramic on the

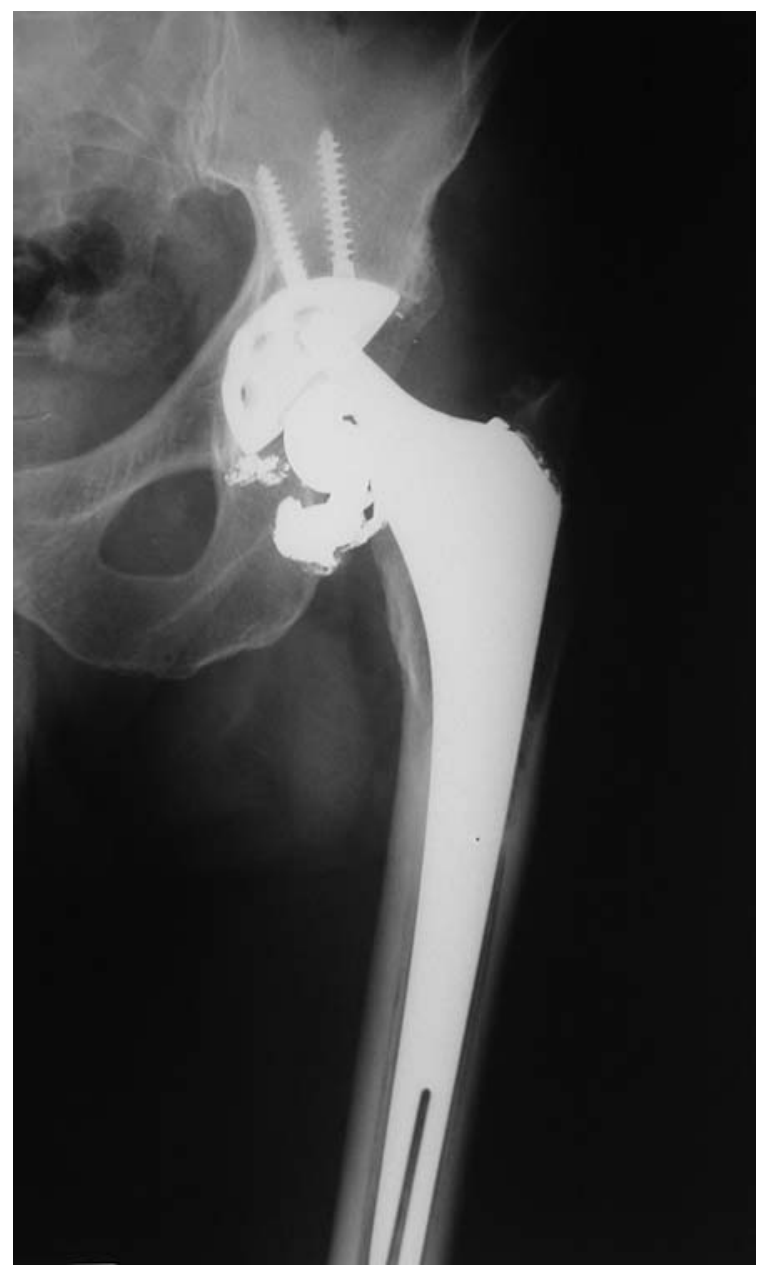

Fig. 1

Pre-operative radiograph showing the fractured ceramic head.

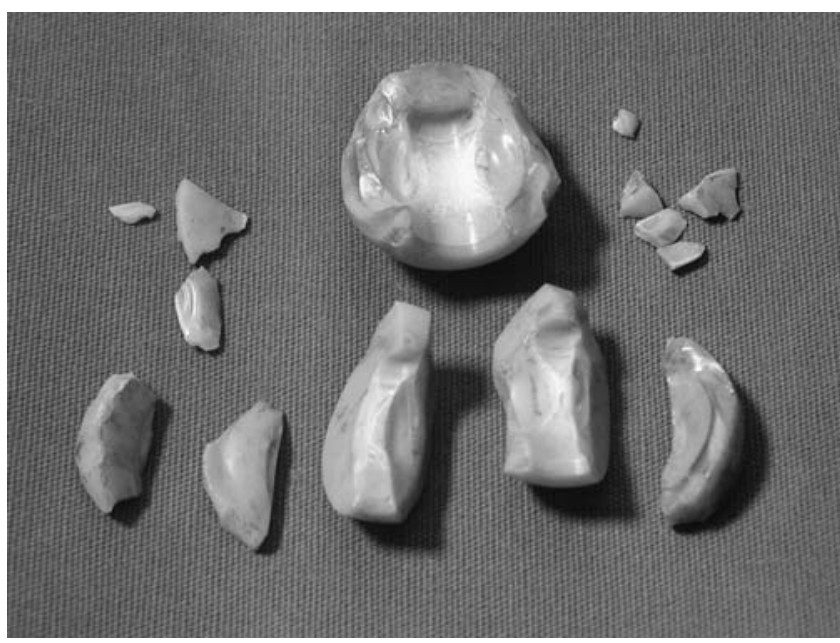

Fig. 2

Photograph of fragments of the retrieved head. 


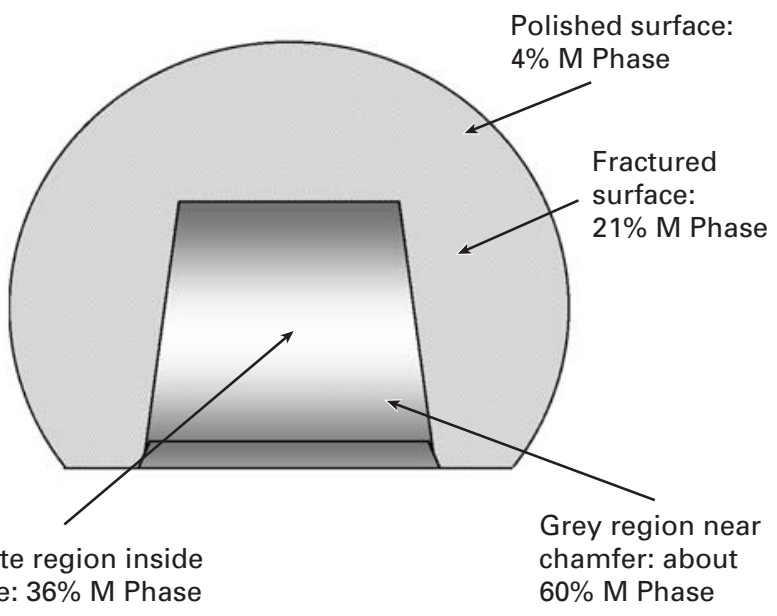

Fig. 3

Diagram of the content in the monoclinic (M) phase measured in different surfaces of the fractured head.

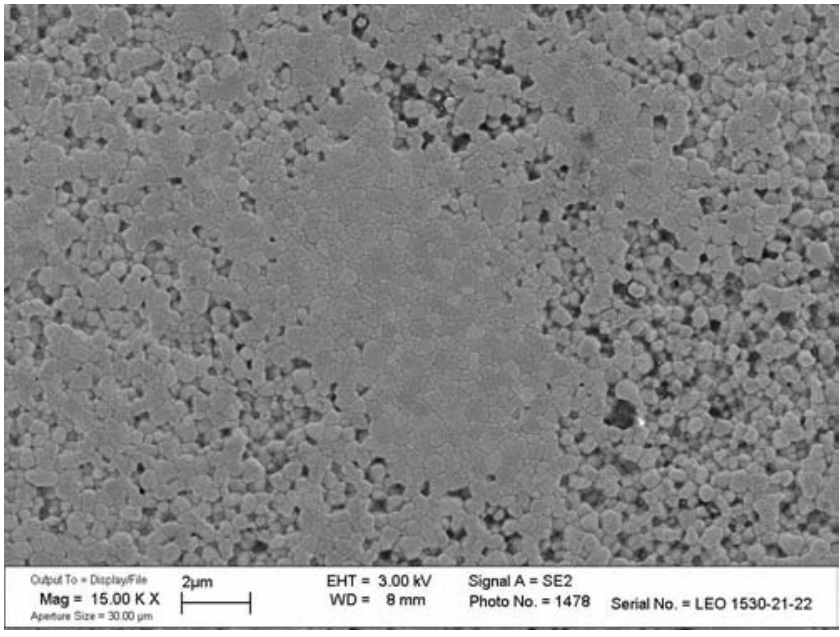

Fig. 4

Photograph of an agglomerate surrounded by low-density material.

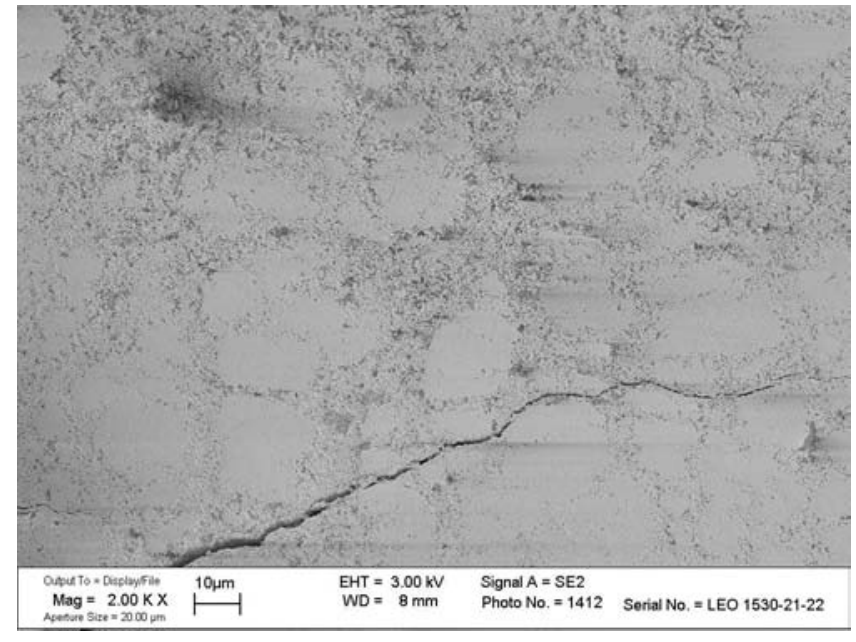

Fig. $5 a$

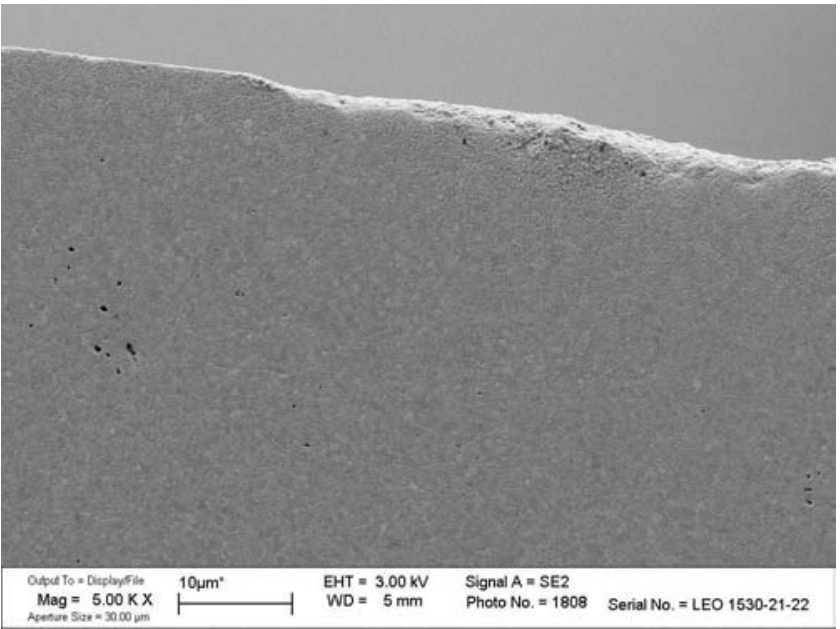

Fig. $5 b$

Figure $5 \mathrm{a}$ - Detail of a crack developed in the low-density matrix between the agglomerates. Figure $5 \mathrm{~b}$ - Microstructure of the bulk of the head reported for comparison.

surface of polished sections cut from most of the femoral head, was formed by tetragonal grains only (Fig. 3).

FEG-SEM analysis of the ceramic. The material in the taper was formed by agglomerates of submicron-sized grains of diameter about $10 \mu \mathrm{m}$ (Fig. 4), in a matrix showing a fine and even residual porosity, crossed by cracks (Fig. 5). The porous matrix appeared dark on the SEM images because of the residue of organic binders from the polish used in the preparation of the samples. This porous zone extended up to $0.5 \mathrm{~mm}$ beneath the original surface of the taper (Fig. 6). Grains in the agglomerates and in the dense part of the head were of the same size $(0.301 \pm 0.007 v \mathrm{~s}$ $0.292 \pm 0.013 \mu \mathrm{m})$.
Histological findings. Histological examination of the retrieved tissue showed many mononuclear histiocyte-like cells in a stroma of collagen fibres. Metal particles were observed inside these cells or close to vessels scattered through the stroma (Fig. 7). Zirconia particles could be grouped into two sizes, less than $2 \mu \mathrm{m}$ in diameter and yellow-amber in colour, and more than $10 \mu \mathrm{m}$ and dark in colour. Under polarised light ceramic particles showed a weak birefringence, slightly different from that typically exhibited by polyethylene particles. In our case, no giant cells were observed in the membrane. SEM-EDAX of periprosthetic tissues showed that the zirconia particles either had a polygonal shape or, more rarely, were rounded. Smaller particles were usually scattered within the 
tissue, but they also appeared as aggregates measuring 10 to 15 $\mu \mathrm{m}$ in diameter.

\section{Discussion}

Based on the information sent to the patient in January 2003 by the surgeon who performed the primary surgery in 1999, and on the data regularly updated by Agence Française de Sécurité Sanitaire des Produits de Santé (AFFSPS), the ceramic head belonged to a batch in which there had been fractures in $42 \%$ up to March 2003, and all of which had occurred between 21 and 46 months after surgery. This batch of heads was manufactured by the following process 1) powder batch preparation; 2) spray-drying granulation of the powder; 3 ) pressing of the granulate into a ball shape reaching a density of about $50 \%$ theoretical density (TD); 4) thermal treatment (presintering) in a continuous (tunnel) furnace, reaching a density $\geq 95 \%$ TD (intermediate density); 5) full densification by hot isostatic pressing in gas (e.g. $1200^{\circ} \mathrm{C}, 1000 \mathrm{MPa}$ ) reaching a density of about $100 \mathrm{TD}$ (final density); 6) grinding and polishing of the ball to the final diameter, roundness and roughness; 7) hard matching of the taper within the ball; and 8) proof testing, laser marking and final inspection.

Our analyses of the removed specimens showed that the crack which led to the fracture started at the surface of the taper and had the same heterogeneous structure as the core of the head, as seen on SEM (Figs 4 to 6). During powder-compaction to form the ball, an uneven radial distribution of density may have occurred and persisted after presintering. The homogeneous size of grain agglomerates in the centre of the ball, about $10 \mu \mathrm{m}$, suggests that they may have been residuals of the powder granulation process by spray drying. The defects did not 'heal' during the fast presintering cycle in the tunnel furnace used in place of the usual batch furnace (kiln). A retrospective study has shown a correlation between the high rates of fracture of zirconia femoral heads and the low intermediate density after presintering.

The head undergoes hot isostatic pressing performed to achieve very high density to enhance the reliability of the ceramic components. ${ }^{31}$ In order to achieve uniform density by hot isostatic pressing it is mandatory that high-pressure gas $(1000 \mathrm{MPa})$ does not enter the presintered ceramic. It is necessary to achieve closed porosity at the surface during presintering, when the ceramic displays an intermediate density.

It is likely that closed porosity was not achieved in the case of this femoral head. Furthermore, high-pressure gas may have entered the core of the material during hot isostatic pressing, and its microstructure may have remained heterogeneous. The drilling of the head for the taper, in the presence of sintering defects, may have enhanced the development of microcracks without affecting the short-term mechanical properties. Subcritical crack growth does occur on clinical use, as a result of the tensile stresses on the taper surface in a wet environment. In these conditions the T-M and spontaneous transition of unconstrained tetragonal zirconia grains at the cracked surfaces may occur and propagation of the crack, enhanced by cyclic stresses, eventually leads to fracture several months after surgery, as in this case.

The fracture of the head resulted in the release of abundant debris of inert materials, mainly ceramic and metal into the joint space. Polyethylene particles were not detected. Most of this debris may have been generated in the two-month interval between the fracture of the head and revision surgery. Diffuse metallosis was observed locally, attributable to the rubbing of fragments against the naked taper and neck of the stem. Histo-



Fig. 6

Transverse section of the taper surface showing the degraded core of the head with cracks propagating in the dense material.

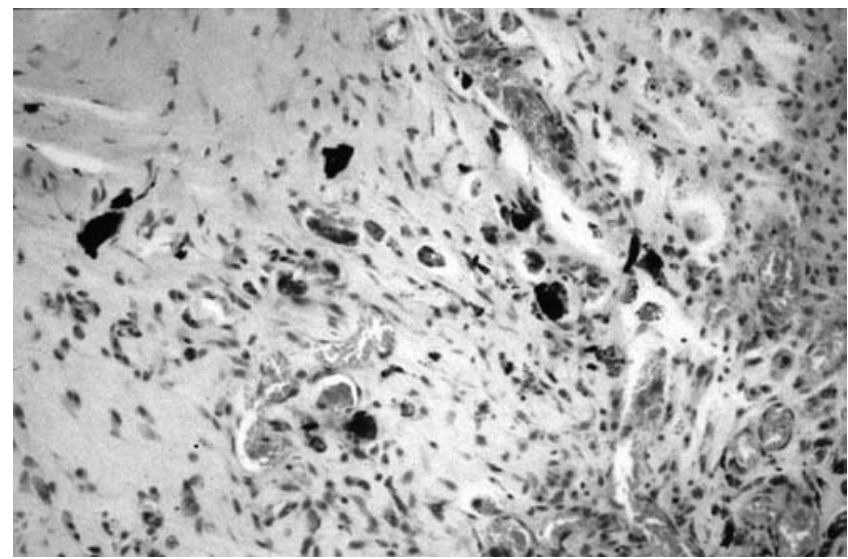

Fig. 7

Histological section showing the presence of a large amount of metal particles close to vessels.

logical examination of periprosthetic tissues showed the prevalence of mononuclear cells containing metal and ceramic debris in the absence of polynuclear giant cells. Some vessels were seen containing or surrounded by metal particles but not by ceramic particles.

Notwithstanding the presence of considerable ceramic and metal debris, there were no osteolytic lesions either in the femur or in the acetabulum. This absence of osteolysis may have been related to the short period of poor function with the broken head, but also to a low risk of bone resorption in zirconia-polyethylene coupling reported even at follow-up at five years. ${ }^{17,32}$ However, it may also have been related to the absence of giant cells as observed in experimental studies in which the periprosthetic tissues were seeded with ceramic particles in the absence of metals and polymers. $^{33}$ 
Based on the experimental findings and on the mechanisms discussed it may be concluded that the critical crack started from the taper surface. The ceramic head is subjected to the highest tensile stresses in the presence of non-homogeneous material, produced during ceramic processing. In a physiological wet environment the cyclic loading contributed to slow propogation of cracks leading to delayed fracture of the head. The T-M transition, measured on the inner surfaces probably, due to the lack of matrix constraint in the wet environment, played a secondary role in the fracture of the component. The tissue reactions observed in this case are not specific to zirconia debris.

It is worth noting that T-M transition was observed on the already cracked surfaces but not on the external polished surface of the ball head. The degradation of the properties which led to the fracture cannot be linked to the metastable nature of zirconia, which can be exploited to enhance the mechanical properties of ceramic components in many biomedical and engineering applications. The results of our examination of the retrieved fragments, emphasises the importance of accuracy in process control and validating in the production of 'high-tech' ceramic materials.

No benefits in any form have been received or will be received from a commercial party related directly or indirectly to the subject os this article.

\section{References}

1. International Organization for Standardization TC 150, Implants for Surgery ISO 13356: Ceramic materials based on yttria-stabilized tetragonal zirconia (Y-TZP), 1997

2. Piconi C, Maccauro G. Zirconia as a ceramic biomaterial. Biomaterials 1999;20: $1-25$.

3. Yamamuro T. Zirconia ceramics for the femoral head of hip prosthesis. In: Sedel L, Cabanela ME, eds. Hip surgery: materials and developments, London: Blackwell Science Inc, 1998:41-4.

4. Calés B. Zirconia as a sliding material: histologic, laboratory and clinical data. Clin Orthop 2000;379:94-112.

5. Bioproimplants http://www.bioproimplants.com/hip tara head (accessed 21/06/04).

6. Calandruccio JH, Jobe MT. Arthroplasty of the thumb carpometacarpal joint. Seminars in Artrop 1997:82:135-47

7. Kohal RJ, Papavasiliou G, Kamposiora P, Tripodakis A, Strub JR. Three-dimensional computerized stress analysis of commercially pure titanium and yttrium-partially stabilized zirconia implants. Int J Prosthodont 2002;15:189-94.

8. Kakehashi Y, Lüthy H, Naef R, Wohlwend A, Schärer. A new all-ceramic post and core system: clinical, technical and in vitro results. Int J Periodont Rest Dent 1998:18:587-93.

9. Weber W, Rieger W. ZrO2-TZB in dentistry: material, properties and applications [abstract]. Key Eng Mater 2001;192-195:841-4.

10. Luthard RG, Sandkuhl O, Reitz B. Zirconia-TZP and alumina: advanced technologies for the manufacture of single crowns. Eur J Prosthodont Restor Dent 1999;7: 113-19.

11. Hummer CD 3rd, Rothman RH, Hozack WJ. Catastrophic failure of modular zirconia-ceramic femoral head components in total hip arthroplasty. J Arthroplasty 1995; 10:848-50
12. Calés B. Advantages of zirconia for ceramic-on-ceramic THP. In: Rieker C, Oberholtzer S, Wyss C, eds. World Tribology Forum in arthroplasty, Bern etc: Hans Huber, 2001:309-18.

13. Arnaud JM, Charissoux JL, Setton D, et al. Utilisation de al zircone pour les têtes 22.2 de PTH: a propose de 10 fractures de têtes [abstract]. Presented at 30é Meeting de la Societé Othopédique de l'Ouest, Pont l'Aubee, France, 1997.

14. Oonishi H, Amino H, Ueno M, Tunoki H. Concept and design with ceramics for total hip and knee replacement. In: Sedel L, Willmann G, eds. Reliability and longterm results of ceramics in orthopaedics, Stuttgart: Thieme Verlag, 1999:7-28.

15. Ueno M, Okimatsu H, Amino H, et al. Experience on zirconia femoral heads in Japan. Presented at the 6th World Biomaterials Conference, Society for Biomaterials 2000

16. Langlais F, Passutti N, Hernigou P. Les couples céramique/polyethyléne: alumine ou zircone? Ann Orthop Quest 2000;32:305-12.

17. Allain J, Le Mouel S, Goutaillier D, Voisin MC. Poor eight-year survival of cemented zirconia-polyethylene total hip replacement. J Bone Joint Surg [Br] 1999; 81-B:835-42

18. Haraguchi K, Sugano N, Nishii T, et al. Phase transformation of a zirconia ceramic head after total hip arthroplasty. J Bone Joint Surg [Br] 2001;83-B:996-1000.

19. Hernigou $\mathbf{P}$, Bahrami T. Etude comparative à 12 ans de recul de deux séries de prothèses totales de hance avec couples zircone/polyéthylène et alumine/polyéthylène [abstract]. Rev Chir Orthop 2002;88(Suppl):2528.

20. Clarke IC, Manaka M, Green D, et al. Current status of zirconia implants: clinical and laboratory studies [abstract]. Procs 70th AAOS, 2003 New Orleans, Scientific Exhibit SE203:652.

21. Catledge SA, Cook M, Vohra YA, et al. Surface crystalline phases and monoindentation hardness of explanted zirconia femoral heads. J Mater Sci Mater Med2003;14: 863-7.

22. Dietrich A, Heimann RB, Willmann G. The color of medical-grade zirconia (TYTZP). J Mater Sci Mater Med 1996;7:559-65.

23. Swab JJ. Low temperature degradation of Y-TZP materials. J Mater Sci 1991;26: 6706-14.

24. Lepistö TT, Mäntylä TA. Degradation of TZP ceramics in humid atmosphere. In: Clark DE, Zoitos BK, eds. Corrosion of glass, ceramics and ceramics superconductors: principles, testing, characterisation and applications. Park Ridge: Noyes Publications 1992:492-513

25. Blaise L, Villermaux F, Calès B. Ageing of zirconia: everything you wanted always to know [abstract]. Key Engineering Materials 2001;192-195:553-6.

26. Tsubakino $\mathbf{H}$, Nozato R, Hamamoto $\mathbf{M}$. Effect of alumina addition on the tetragonal-to-monoclinic phase transformation in zirconia-3\% mol yttria. J Am Ceram Soc 1991;74:440-3

27. Burger W, Richter HG, Piconi C, et al. New Y-TZP powders for medical grade zirconia. J Mater Sci Mater Med 1997;8:113-18.

28. Maccauro G, Romanini E, Dall'Acqua D, Piconi C, De Santis E. Una scheda di valutazione degli impianti protesici rimossi. Giornale Italiano di Ortopedia e Traumatologia 1998;24:375-81.

29. International Organization for Standardization TC 150, Implants for Surgery ISO 12891: Retrieval and analysis of surgical implants - part 4: analysis of retrieved ceramic surgical implants, 2000.

30. Richter HG. Fractorgraphy of bioceramics. Key Eng Mater 2002;223:157-80.

31. Calès B. Y-TZP zirconia ceramic hip joint heads: key-issues for a high reliability. In: Ravaglioli A, ed. Fourth Euro-Ceramics Vol 8 Bioceramics. Faenza: Gruppo Editoriale Faenza Editrice S.p.A., 1995;8:45-42.

32. Jenny J-Y, Boeri C, Tavan A, Schlemmer B. Results en fonction du couple de frottement [abstract]. Rev Chir Orthop 1998;84:111-12.

33. Maccauro G, Piconi C, Muratori F, De Santis V, Burger W. Tissue reactions to ceramic wear debris: clinical cases vs. animal model. In: Zippel H, Dietrich M, eds. Bioceramics in joint arthroplasty. Darmstadt Steikopff Verlag. 2003: 81-7. 